\title{
BMJ Open NutriQuébec: a unique web-based prospective cohort study to monitor the population's eating and other lifestyle behaviours in the province of Québec
}

Annie Lapointe (D) , ${ }^{1}$ Catherine Laramée, ${ }^{1}$ Ariane Belanger-Gravel, ${ }^{1,2,3}$ David L Buckeridge, ${ }^{4}$ Sophie Desroches, ${ }^{1,5}$ Didier Garriguet, ${ }^{6}$ Lise Gauvin, ${ }^{7,8}$ Simone Lemieux, ${ }^{1,5}$ Céline Plante, ${ }^{9}$ Benoit Lamarche ${ }^{1,5}$

To cite: Lapointe A, Laramée $\mathrm{C}$, Belanger-Gravel A, et al. NutriQuébec: a unique web-based prospective cohort study to monitor the population's eating and other lifestyle behaviours in the province of Québec. BMJ Open 2020;10:e039889. doi:10.1136/ bmjopen-2020-039889

- Prepublication history and additional materials for this paper is available online. To view these files, please visit the journal online (http://dx.doi. org/10.1136/bmjopen-2020039889).

Received 29 April 2020 Revised 22 September 2020 Accepted 11 October 2020

Check for updates

(C) Author(s) (or their employer(s)) 2020. Re-use permitted under CC BY-NC. No commercial re-use. See rights and permissions. Published by BMJ.

For numbered affiliations see end of article.

Correspondence to

Dr Benoit Lamarche;

benoit.lamarche@fsaa.ulaval.ca

\section{ABSTRACT}

Introduction The epidemic of non-communicable diseases including cardiovascular diseases and type 2 diabetes is attributable in large part to unhealthy eating and physical inactivity. In the fall of 2016, the Québec government launched its first-ever Government Health Prevention Policy (Politique gouvernementale de prévention en santé (PGPS)) to influence factors that lead to improved health status and quality of life as well as reduced social inequalities in health in the population of Québec. NutriQuébec is a web-based prospective open cohort study whose primary aim is to provide essential data for the evaluation of the PGPS on the Québec population's eating and other lifestyle behaviours over time.

Methods and analysis Over a first phase of 3 years, NutriQuébec will enrol 20000 adults living in the province of Québec in Canada through a multimedia campaign designed to reach different segments of the population, including subgroups with lower socioeconomic status. Participants will be invited to complete on a web platform nine core questionnaires on a yearly basis. Questionnaires will assess several dimensions related to lifestyle, including eating and physical activity behaviours, as well as a large number of personal characteristics and global health status. Temporal trends in eating and lifestyle behaviours will be analysed in relation to the implementation of the PGPS to provide essential data for its evaluation at a population level. Data analyses will use sociodemographic weights to adjust responses of participants to achieve, so far as is possible, representativeness of the adult Québec population. Ethics and dissemination Université Laval Research Ethics Board approved the NutriQuébec project. Data analysis, presentations in conferences and publication of manuscripts are scheduled to start in 2020.

Trial registration number NCT04140071.

\section{INTRODUCTION}

The burden of non-communicable diseases continues to increase worldwide, and Québec (Canada) is no exception. For example, the prevalence of diabetes has doubled since the early 2000s. ${ }^{1}$ This epidemic of
Strengths and limitations of this study

- NutriQuébec is an entirely web-based prospective open cohort study that uses population-specific pretested and validated questionnaires, including a web-based 24-hour recall.

- Detailed information on dietary habits but also on several other health dimensions such as physical activity, sleep and quality of life will be obtained on a yearly basis in NutriQuébec, thus providing unparalleled data of the Québec adult population.

- Recruitment and retention strategies used in NutriQuébec are based on a needs assessment study among low socioeconomic status populations, which are often under-represented in health research.

- One of the eligibility criteria to participate to NutriQuébec is having access to the internet, which may be a barrier among very low socioeconomic status populations.

- Achieving representativeness of the Québec adult population in a web-based study poses a great challenge, even after accounting for sociodemographic weights.

non-communicable diseases is attributable in large part to poor lifestyle behaviours such as smoking and physical inactivity, but also and perhaps most prominently to unhealthy eating. Indeed, results from a recent systematic analysis of 195 countries suggest that $20 \%$ of all deaths from cardiovascular disease, cancer and type 2 diabetes in 2017 were due to poor diet. ${ }^{2}$ Overconsumption of sodium and low consumption of whole grain products and fruits alone accounted for more than half of deaths related to poor eating. Low socioeconomic status (SES) populations, that is, populations experiencing financial deprivation and with limited education, are particularly at risk of developing noncommunicable diseases related to unhealthy 
lifestyle behaviours and contribute disproportionately to the overall costs of the health system. ${ }^{3-6}$

Although healthy lifestyles have a significant impact on the risk of non-communicable diseases, ${ }^{7}$ improving lifestyle behaviours in the population remains a major challenge. A recent study from our group has shown that French-speaking adults from the province of Québec in Canada have a diet of relatively poor quality, with only $23.6 \%$ achieving the Canadian recommendations for daily consumption of vegetables and fruits. ${ }^{8}$ In an unprecedented attempt to address health issues in the population, the Québec government launched in 2016 its first-ever Government Health Prevention Policy (Politique gouvernementale de prévention en santé (PGPS)). ${ }^{9}$ The main objective of the PGPS is to act on factors that improve the health status and quality of life of the Québec population and reduce social inequalities in health. One of the nine targets of the PGPS is that by 2025, more than half of the Québec population consumes a minimum of five vegetables and fruits on a daily basis. The Québec government has also developed an interministerial action plan ${ }^{10}$ to achieve the targets of the PGPS. One of these actions is to monitor and analyse the evolution of the adult population's eating behaviours. Considering that provincial and national surveys providing nutrition data (Québec Population Health Survey (QPHS) ${ }^{11}$ and Canadian Community Health Survey-Nutrition (CCHS-Nutrition) ${ }^{12}$ are cross-sectional, they do not allow for assessment of individual trajectory change of eating and other behaviours. Their very low and irregular frequency also limit our ability to monitor changes over shorter periods of time. Access to prospective dietary intake and other lifestyle data in Québec will undoubtedly facilitate decision-making, while providing insightful information for the evaluation of the PGPS and its action plan in improving the population's health through healthier eating and lifestyle behaviours.

Thus, the NutriQuébec project (referred to as NutriQuébec) was incepted with the intent to provide essential longitudinal data for the evaluation of the PGPS and related action plan in eating and other lifestyle behaviours of the Québec population over time. NutriQuébec data will be collected entirely through the web. The aim is to generate results that can be generalised to the Québec adult population so far as is possible, with particular efforts to reach low SES populations, who are typically under-represented in health research. ${ }^{13}$ The present paper describes the architecture, the vision and the methodology of NutriQuébec, which was launched in June 2019. NutriQuébec is funded for 4 years by the Québec government (2018-2022), which will allow for sequential measurements at baseline (2019), year 1 , and year 2 of follow-up. Since NutriQuébec is intended as a long-term prospective study of the Québec population, strategies to obtain additional funding to sustain the cohort over a 25-year period will be implemented starting in 2020.

\section{Objectives of NutriQuébec}

NutriQuébec aims to: (1) create a cohort of men and women that is as representative as possible of the Québec adult population; (2) prospectively monitor changes in lifestyle behaviours, prominently eating habits but also physical activity and sleeping behaviours of the Québec adult population; (3) identify the factors associated with social inequalities in health in the context of healthy eating; (4) cross-reference self-reported data on lifestyle behaviours with the participants' health status and living environment; (5) assess the potential impact of public health programmes and policies over time; (6) conduct ad hoc surveys on public health issues related to nutrition and health among specific subgroups of active participants in NutriQuébec.

\section{METHODS AND ANALYSIS \\ Development of the infrastructure and tools used in NutriQuébec \\ The NutriQuébec website}

The website (NutriQuébec.com) provides the required information for interested adults to fully understand the nature and objectives of the project and the involvement required for participation. ${ }^{14}$ The website users have the opportunity to consult a 'Frequently Asked Questions' section with list answers to the most frequently asked questions or to send an email to the project team. The website also provides access to news and publications related to the project as well as NutriQuébec's Facebook page. To facilitate navigation and understanding, the website was built according to good practices in terms of web ergonomics and health literacy. ${ }^{15}$

\section{The web-based 24-hour dietary recall}

We have recently developed and validated a selfadministered and automated web-based 24-hour dietary recall (the R24W) for clinical research and large population-based studies such as NutriQuébec. ${ }^{16-21}$ The full methodology behind the R24W has been previously described in detail. ${ }^{17}$ Briefly, the R24W is inspired by the automated multiple-pass method of the US Department of Agriculture ${ }^{22}$ and guides participants to indicate all foods and beverages consumed during the previous day. The $\mathrm{R} 24 \mathrm{~W}$ presents a mandatory $5 \mathrm{~min}$ tutorial at the first login to provide instructions and facilitate its use for participants with lower literacy skills. The R24W allows for selecting foods and beverages consumed by browsing through a structured list of foods or by using a search engine. It also contains images to help assess the size of portions consumed at any given time. Participants who do not find a specific food item when filling out the R24W has access to an open-ended field where this can be specified. The R24W includes additional questions about (1) factors that influence nutritional needs (age, sex, pregnancy and breastfeeding), (2) the context of the meal or snack (time, place, presence of others and in front or not of a screen during the meal), (3) the level of representativeness of the day's diet compared with the usual diet and (4) the consumption of natural health products, vitamins and mineral supplements. In order to minimise recall bias, the $\mathrm{R} 24 \mathrm{~W}$ provides a reminder of eight frequently 
forgotten food categories at the end of each meal as well as at the end of the day and displays a detailed summary of the food and beverages consumed at the end of the day. The R24W generates detailed data such as energy, macronutrient and micronutrient intakes as well as different healthy eating indices that are readily available to researchers for analysis. ${ }^{23}$ The R24W is adapted for use on a phone, tablet and a computer. The R24W performs well when reporting consumption of food items and has strong relative validity and low misclassification rate compared with standard references methods. ${ }^{16} 181921$

\section{Piloting NutriQuébec: the PREDISE Study}

The PREDISE (PRÉDicteurs Individuels, Sociaux et Environnementaux) Study is a multicentre cross-sectional study using the R24W to collect and examine individual, social and environmental data on factors associated with adherence to dietary recommendations. ${ }^{8} 24$ Participants $(n=1147)$ from five regions of the province of Québec completed 12 online questionnaires on attitude, behaviours, preferences and knowledge related to food, ${ }^{25-29}$ as well as physical activity, personal characteristics and health status. Dietary intakes were also assessed on three occasions using the R24W. The PREDISE Study showed: (1) the feasibility of using the web interface to obtain detailed data on dietary intakes and determinants of healthy lifestyles of the Québec population; and (2) the team's capacity to achieve a project of the scope of NutriQuébec with the tools and resources available for this project.

\section{Needs assessment study}

A needs assessment study was conducted prior to the development of the NutriQuébec project to identify factors that will help the recruitment of individuals with low SES, thereby contributing to the generalisability of the results to the entire Québec population. This preliminary research consisted of four focus groups and a populationbased survey identifying the advantages, disadvantages, facilitating factors and perceived barriers towards the participation in the NutriQuébec survey as well as identifying their preferences regarding recruitment methods and their concerns about the use, security and sharing of data. ${ }^{30}$ The preoccupations and preferences identified in this needs assessment study were taken into consideration when crafting questionnaires and designing the NutriQuébec website, and will also be taken into account in all phases of the broader NutriQuébec data collection process, including the retention phases.

\section{Study design and participants}

NutriQuébec is an open cohort with continuous and uninterrupted recruitment over the study duration, which is currently funded for a period of 4 years. The target sample size is 20000 adults living in Quebec based on a non-probability sample. Adults aged 18 years and over with a residential address in the province of Québec are eligible to participate in NutriQuébec. There are no exclusion criteria, other than not being able to read and understand French or English. Participating to NutriQuébec also requires access to the internet (with a phone, tablet or computer) and have an active email address.

\section{Recruitment and registration}

A multimedia campaign will be unfolded to reach the target population throughout the province of Québec, taking into account the results from the needs assessment study described above. More specifically, television, radio and print interviews will be organised periodically. Key leading figures in the area of food and health will be solicited to promote the project on various media platforms. The project will also be publicised on social networks, including on the NutriQuébec Facebook page. ${ }^{14}$ The Québec government and several of its community partners will be invited to promote NutriQuébec via their website, newsletters and/or networks. In addition, recruitment ads will be distributed through several channels, including: (1) email lists from Université Laval, partners and other universities in Québec; and (2) public places such as community centres, health institutions and businesses. All of the above-mentioned recruitment methods will invite individuals interested in the study to visit the NutriQuébec website ${ }^{32}$ for more information and to register.

Adults interested to participate access a secure registration form on the PULSAR website via the NutriQuébec website. PULSAR is an interdisciplinary and intersectoral network dedicated to research on sustainable health at Université Laval. ${ }^{33}$ PULSAR offers an integrated, secure environment that follows the strictest standards and practices. In the context of NutriQuébec, PULSAR manages the registration of participants, allows participants to directly manage their personal information and consents, and hosts the research data via a highly secured information technology infrastructure.

After having created an account on the secured PULSAR platform, each individual is invited to provide informed consent to participate in the project, which was approved by Université Laval Ethics Board. Then, identification questions including name, birth date, sex, email, address of residence and preferred language for answer (English or French) are asked. Their eligibility (age and address of residence) is automatically verified by the system on registration. Once registered and having consented, participants are invited through email to complete the core questionnaires by logging into their personal and secured account.

\section{Data collection}

\section{Core questionnaires}

Core questionnaires will be completed on a yearly basis, based on the date of the participants' first registration. These core questionnaires have been selected by the NutriQuébec scientific committee whose members have solid expertise in epidemiology and in tools for 
evaluating lifestyle habits. These questionnaires assess lifestyle behaviours including eating, physical activity, sleep quality, tobacco, substance use as well as personal characteristics, food security and health status. The median time to complete all core questionnaires so far is less than 2 hours (108 min; IQ 85-145 min) in preliminary analyses of the first 1828 participants that completed all core questionnaires in NutriQuébec since June 2019 until February 2020. Participants can fill out questionnaires in any order and at any time during a 30-day period, with the exception of the R24W (see below). Reminder emails are also sent by the system 7 days before the end of the 30 days to participants who have not started or have not completed all questionnaires. All questionnaires have been validated and/or pretested and used in previous studies by our team $^{34-38}$ or in national surveys..$^{11} 123940$ Details about the core questionnaires and median time required for their completion are presented in table 1 .

\section{Eating behaviours}

Participants are invited by email to complete the R24W on three unannounced and non-consecutive days ( 1 weekend day and 2 weekdays) selected randomly by a computer algorithm over a 30-day period. Participants have until midnight to complete each R24W. If an R24W is not completed, a new date consistent with the above criteria is generated by the system when possible. In addition to the R24W, a short validated food frequency questionnaire $^{35}{ }^{36}$ is used to assess usual vegetable and fruit intake over a 7-day period.

\section{Physical activity and sedentary lifestyle}

The physical activity questionnaire includes questions on screen time, active transportation, and work and leisure activities. These questions come from the Godin Leisure-Time Exercise Questionnaire ${ }^{4142}$ the European Prospective Investigation into Cancer and Nutrition physical activity questionnaire, ${ }^{43}$ and the QPHS. ${ }^{11}$ In all cases, these physical activity questionnaires are based on the last 12 months, with the exception of questions on active transportation, which enquires on activities during the last month. The choice of a single or combination of such questionnaires will depend on the planned analyses.

\section{Sleep quality}

Sleep quality is assessed using the Pittsburgh Sleep Quality Index, which identifies sleep disorders over the preceding month. The validity of this questionnaire has been demonstrated in both French ${ }^{37}$ and English. ${ }^{38}$

\section{Substance use}

The substance use questionnaire includes questions on smoking and use of tobacco products, exposure to secondhand smoke, and drug and alcohol use. The questions come from the CCHS ${ }^{12}$ and the QPHS ${ }^{11}$ and have been pretested in both French and English.

\section{Personal characteristics}

The personal characteristics questionnaire includes questions about ethnicity, gender, household composition (eg, type of family, number of children), main activity, education and annual household income. Questions are taken from the CCHS,${ }^{12}$ the QPHS,${ }^{11}$ the Canadian Health Measures Survey ${ }^{40}$ and the Canada census of population. ${ }^{39}$ All questions have been pretested in French and English.

\section{Food security}

Household food security is assessed using the series of questions of the Household Food Security Survey Module from the CCHS, ${ }^{12}$ which have been pretested in both French and English. ${ }^{12}$ These questions address among others the frequency of cutting the size of the meals, skipping meals or not eating in a whole day because there was not enough money for food.

\section{Health status}

The health status questionnaire includes questions on general health, self-reported height and weight, chronic conditions, use of primary healthcare services, changes made to improve health and social provisions. These questions come from the $\mathrm{CCHS}^{12}$ and the $\mathrm{QPHS}^{11}$ and have been pretested in both French and English. Participants are also invited to complete the Medical Outcome Study Short Form (SF-36), which assesses eight dimensions of health: physical functioning, social functioning, role limitations attributed to physical problems, role limitations attributed to emotional problems, mental health, energy and fatigue, pain, general health perception. The SF-36 has been validated in both French and English. ${ }^{34} 45$

\section{Additional questionnaires}

Additional questionnaires may be integrated within the main scheme of NutriQuébec, with a maximum of three yearly solicitations to all participants or to subgroups of participants with specific characteristics. These ad hoc surveys will be developed over the course of the study according to the needs of the Québec government and other research opportunities. As approved by the Ethics Board, time required to fill out each additional questionnaire between core yearly measures will not exceed $20 \mathrm{~min}$.

\section{Incentives for participation}

Results from the needs assessment study suggested that providing feedback was key to promoting participation and retention in NutriQuébec. However, providing feedback in a prospective observational study is arguable because of the risk of influencing behaviours over time. For that reason, the feedback to participants will be limited to a general assessment of one's intakes of vegetables and fruits, whole grain food, sodium, saturated fat and sugary drinks with only succinct references to current recommendations (see online supplemental appendix 1). Although knowledge is a necessary condition for behaviour change, knowledge alone is not considered 
Table 1 List of core questionnaires

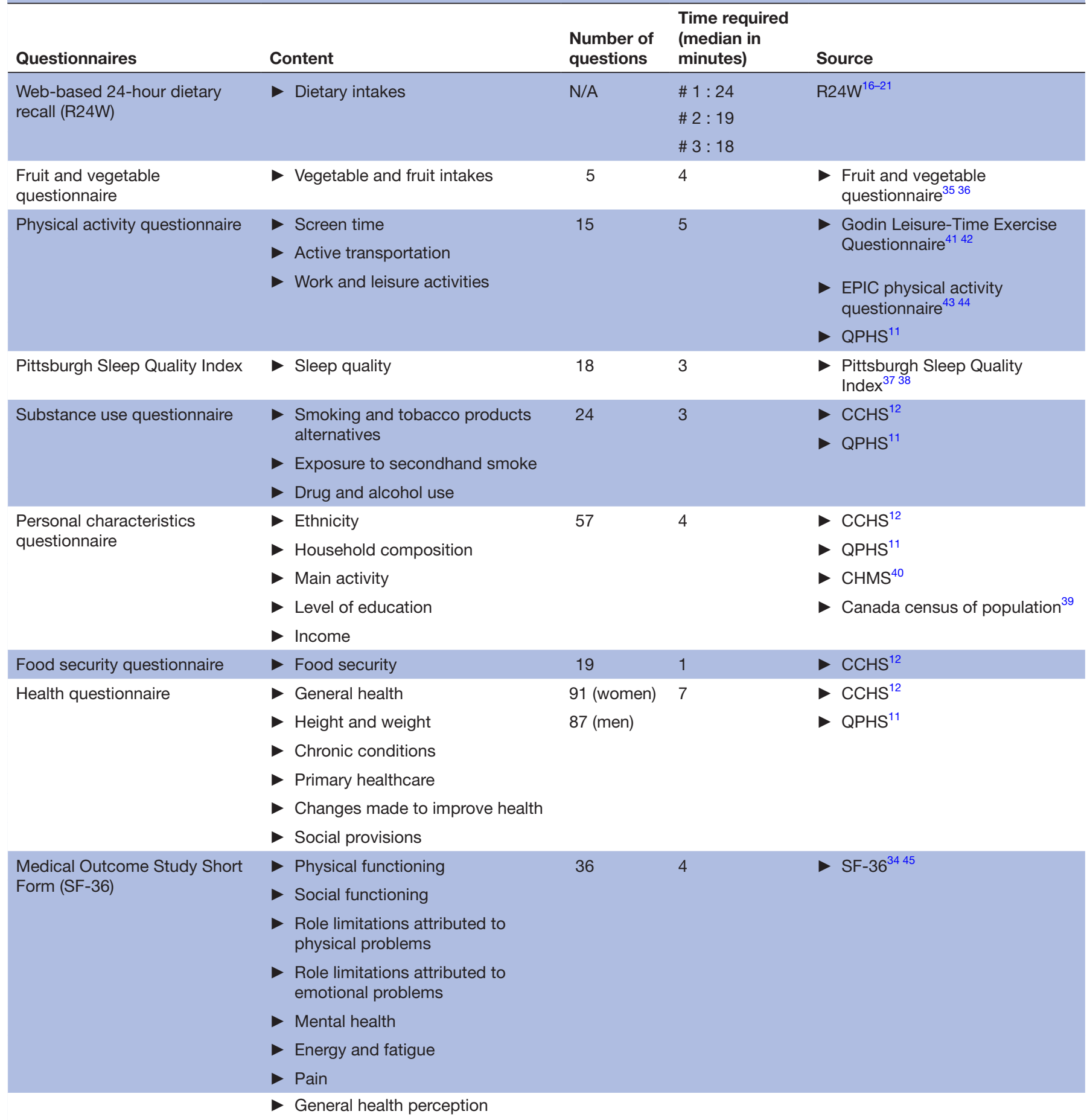

These data are based on preliminary analyses of the first 1828 registered participants in NutriQuébec.

CCHS, Canadian Community Health Survey; CHMS, Canadian Health Measures Survey; EPIC, European Prospective Investigation into Cancer and Nutrition; N/A, not applicable; QPHS, Québec Population Health Survey.

a sufficient condition for impacting behaviours in the long term. ${ }^{46}$ Therefore, personalised basic dietary report provided to all participants who have completed all core questionnaires, including the three R24W will serve as the incentive for participating in the study and completing all questionnaires within the allotted time period.
Data linkage

At enrolment, participants will be asked for their health insurance number if they agree to the linkage of the survey with their medical data. When consented, participants' medical data from the Régie de l'assurance maladie du Québec (RAMQ) and the Ministère de la santé et des 
services sociaux will be linked to data from NutriQuébec to examine associations between eating behaviours, other lifestyle behaviours and the incidence of chronic diseases. The medical data may include disease diagnoses, services in the physicians claims file, hospitalisation in the discharge database, prescribed medications for those on the Public Prescription Drug Insurance Plan and laboratory data. Requests to gain access to such data from the RAMQ will follow traditional channels and regulations. In addition, based on the geographical location of the participants, spatial (or geographical) data describing the built and living environments as well as different sociocultural factors will also be linked with individual-level data to better understand the environmental determinants of overall diet quality among various subgroups of the NutriQuébec participants.

\section{Statistical analyses}

All analyses will apply sociodemographic weight to each participant, as is done with provincial (eg, Institut de la statistique du Québec) and national (eg, Statistics Canada) surveys. Based on recent provincial demographic characteristics (sex, age groups, residence area and education), this weighting will calibrate the NutriQuébec sample of participants to the whole adult Québec population, thereby facilitating generalisation from our results.

Dietary intake data collected using $24 \mathrm{~h}$ dietary recalls are influenced by day-to-day and random variations in dietary intakes (within-individual random error), which causes bias and often attenuates estimated diet-outcome associations. ${ }^{47}$ To mitigate within-individual random error, we will perform regression calibration using all R24Ws completed and use methods such as the National Cancer Institute methods, ${ }^{48-50}$ when appropriate.

Multiple imputations of missing data will be performed considering the extent of missing data, the missing data pattern, the nature of the missing variables and the outcome variables being studied. The number of iterations will vary according to the extent of missing data. The imputation procedure will be conditioned on key analysis variables and sampling weights, variables associated with key variables and variables associated with non-response, which often includes age, sex/gender, household income and education level.

In most cases, analyses will be performed using the block bootstrap method for estimating variance. Trends in eating behaviours, lifestyle behaviours and health status of the Québec population over time as the action plan of the PGPS is implemented will be assessed using mixed linear models, once again taking into account the sociodemographic weight of participants and adjusting for sociodemographic characteristics when required. In general, time and relevant covariables will be considered as fixed effects, and participants as a random effect. The target sample size of 20000 of adult men and women living in all areas of the province of Québec will allow subgroup analyses by several sociodemographic characteristics, including sex, age, body weight status, geographical areas and SES.

\section{Patient and public involvement}

As described above, the public and in particular individuals with a low SES were involved in a needs assessment study to inform NutriQuébec's most promising recruitment and retention strategies.

\section{DISCUSSION}

The scarcity of nutrition surveillance data and the absence of robust data describing eating and lifestyle behaviours prospectively in the Québec population limits the ability of public health and nutrition policymakers in nutrition and health to take evidence-based actions. NutriQuébec, the first large web-based prospective study on diet and health in Québec and in Canada, will provide invaluable data for the evaluation of the PGPS and its action plan and to monitor and analyse the evolution of eating behaviours as well as other dimensions of lifestyle and health among the Québec adult population.

One of the eligibility criteria to participate to NutriQuébec is having access to the internet. In Québec, $95 \%$ of adults use the internet and $91 \%$ consider themselves to be skilled on the internet. ${ }^{51}$ Although men and women use the internet in similar proportions, the rate of internet use varies according to age, income and geographical areas. For example, 96\% of individuals aged 18-24 years use the internet daily compared with $61 \%$ among those aged 65 years or older. ${ }^{52} 53$ The use of the internet also varies according to the income: $74.5 \%$ of individuals in the lowest quartile of income use the internet compared with $95.7 \%$ among those in the highest quartile. ${ }^{54}$ Despite such variations, the penetration of the internet in Québec is high, even among populations with a low SES, which will facilitate outreach and hence increase the likelihood of achieving representativeness.

Considerable efforts will be dedicated to recruiting populations with a low SES, which are known to be difficult to recruit in health-related studies. First, the needs assessment study identified their preoccupations as well as preferred communication strategies to maximise participation in a Web-based project as NutriQuébec. Those preoccupations and preferences have been addressed at different stages of the project and for the development of the different tools. Second, recruitment will specifically target deprived SES populations by including two recruitment strategies that seem particularly effective in reaching these subpopulations: social media, including Facebook and television. ${ }^{55-59}$

Risks of bias should be assessed in cohort studies and concrete measures should be taken to prevent them. ${ }^{60}$ The prevention of potential sources of bias related to missing data and attrition in NutriQuébec will be achieved using different strategies such as: (1) providing an incentive (personalised dietary assessment report) to participants who complete all yearly core questionnaires; 
(2) developing questionnaires that are easy for participants to complete, including those with a low SES; (3) making participants feel that they are contributing to an important and unprecedented research effort on nutrition and health in Québec, (4) being active on social networks and on the NutriQuébec website so that the study is known by as many people as possible and (5) using participants' emails as the communication tool, thus facilitating follow-up. Risks of bias will also be mitigated by applying sociodemographic weights to each study participant according to most recent population surveys, and by comparing data from NutriQuébec and from provincial surveys and disease registries, with adjustments when appropriate.

The necessity of NutriQuébec is undeniable. NutriQuébec addresses an urgent need for measurement and evaluation of public health policies and initiatives in the area of nutrition, food and health in Québec and Canada. By collecting data on changes in eating and other dimensions of lifestyle behaviours of the Québec population, NutriQuébec will provide essential data for the evaluation of the PGPS and its action plan. NutriQuébec will also identify the determinants of dietary behaviours in the Québec population and its impact on health outcomes in the longer term as well as the factors associated with social inequalities in health in the context of healthy eating. Finally, NutriQuébec will provide unique research and collaboration opportunities to multidisciplinary researchers in Québec and in Canada.

\section{ETHICS AND DISSEMINATION}

NutriQuébec was approved by Université Laval Research Ethics Board (2018-042 Phase II A6/09-04-2020). Results in future written communications will be reported in accordance with the Strengthening the Reporting of Observational Studies in Epidemiology statement. Data analysis, presentations in conferences and publication in peer-reviewed academic journals are scheduled to start as early as 2020. In addition, results will be made available on the NutriQuébec website for participants and researchers.

\section{Author affiliations}

${ }^{1}$ Centre NUTRISS, INAF, Université Laval, Quebec City, Quebec, Canada

${ }^{2}$ Department of Information and Communication, Université Laval, Quebec city,

Quebec, Canada

${ }^{3}$ Quebec Heart and Lung Institute, Quebec city, Quebec, Canada

${ }^{4}$ School of Population and Global Health, McGill University, Montreal, Quebec,

Canada

${ }^{5}$ School of Nutrition, Université Laval, Quebec City, Quebec, Canada

${ }^{6}$ Health Analysis Division, Statistics Canada, Ottawa, Ontario, Canada

${ }^{7}$ Centre de recherche du CHUM, Centre Hospitalier de l'Université de Montréal,

Montreal, Quebec, Canada

${ }^{8}$ Department of Social and Preventive Medicine, Université de Montréal, Montreal, Quebec, Canada

${ }^{9}$ Institut national de santé publique du Québec, Quebec City, Quebec, Canada

Acknowledgements The authors thank the FRQS-funded Cardiometabolic Health, Diabetes and Obesity Research Network (CMD0) for their financial support for the needs assessment study and the NutriQuébec website creation. The authors also thank Serge Hercberg and the NutriNet-Santé Study team in France for their support and expertise in the development of the NutriQuébec project. Finally, the authors thank the network for sustainable health research from Universite Laval (PULSAR) for their support and expertise in data security and data sharing.

Contributors AL, CL, AB-G, DLB, SD, DG, LG, SL, CP and BL designed the NutriQuébec project. AL, CL and BL drafted the manuscript. All authors read and approved the final version of the manuscript.

Funding This work was supported by the Québec government (2018-2022).

Competing interests None declared.

Patient consent for publication Not required.

Provenance and peer review Not commissioned; externally peer reviewed.

Supplemental material This content has been supplied by the author(s). It has not been vetted by BMJ Publishing Group Limited (BMJ) and may not have been peer-reviewed. Any opinions or recommendations discussed are solely those of the author(s) and are not endorsed by BMJ. BMJ disclaims all liability and responsibility arising from any reliance placed on the content. Where the content includes any translated material, BMJ does not warrant the accuracy and reliability of the translations (including but not limited to local regulations, clinical guidelines, terminology, drug names and drug dosages), and is not responsible for any error and/or omissions arising from translation and adaptation or otherwise.

Open access This is an open access article distributed in accordance with the Creative Commons Attribution Non Commercial (CC BY-NC 4.0) license, which permits others to distribute, remix, adapt, build upon this work non-commercially, and license their derivative works on different terms, provided the original work is properly cited, appropriate credit is given, any changes made indicated, and the use is non-commercial. See: http://creativecommons.org/licenses/by-nc/4.0/.

ORCID iD

Annie Lapointe http://orcid.org/0000-0001-7081-4809

\section{REFERENCES}

1 Institut national de santé publique du Québec. Prévalence dsu diabète pour la population d'un an et plus, années financières 20002001 2016-2017. Système intégré de surveillance des maladies chroniques du Québec (SISMACQ). Rapport de l'onglet plan national de surveillance produit par l'Infocentre de santé publique l'Institut national de santé publique du Québec, 2019.

2 GBD 2017 Diet Collaborators. Health effects of dietary risks in 195 countries, 1990-2017: a systematic analysis for the global burden of disease study 2017. Lancet 2019;393:1958-72.

3 Loucks EB, Lynch JW, Pilote L, et al. Life-Course socioeconomic position and incidence of coronary heart disease: the Framingham offspring study. Am J Epidemiol 2009;169:829-36.

4 Bird Y, Lemstra M, Rogers M, et al. The relationship between socioeconomic status/income and prevalence of diabetes and associated conditions: a cross-sectional population-based study in Saskatchewan, Canada. Int J Equity Health 2015;14:93.

5 Gershon AS, Dolmage TE, Stephenson A, et al. Chronic obstructive pulmonary disease and socioeconomic status: a systematic review. COPD 2012;9:216-26.

6 Marmot M, Friel S, Bell R, et al. Closing the gap in a generation: health equity through action on the social determinants of health. Lancet 2008;372:1661-9.

7 World Health Organization. Preventing chronic diseases a vital investment. Available: https://www.who.int/chp/chronic_disease_ report/contents/part1.pdf?ua $=1$

8 Brassard D, Laramée C, Corneau L, et al. Poor adherence to dietary guidelines among French-speaking adults in the province of Quebec, Canada: the PREDISE study. Can J Cardiol 2018;34:1665-73.

9 Ministère de la santé et des services sociaux. Politique gouvernementale de prévention en santé. La direction des communications du ministère de la santé et des services sociaux. Québec: Gouvernement du Québec, 2016.

10 Ministère de la santé et services sociaux du Québec. Plan d'action interministériel 2017-2021 de la Politique gouvernementale de Prévention en santé, 2017. Available: http://publications.msss.gouv. qc.ca/msss/document-002035/

11 Institut de la statistique du Québec. Québec population health survey (QPHS) 2008 and 2014-2015. version current 2015 [online]. Available: http://www.stat.gouv.qc.ca/enquetes/fiche_enquete_an.html\#171 [Accessed 13 Jul 2020]. 
12 Statistics Canada. Canadian community health survey (CCHS). version current 27 November 2019 [online]. Available: http://www23. statcan.gc.ca/imdb/p3Instr.pl?Function=getInstrumentList\&ltem_ld = 260675\&UL=AV [Accessed 13 Jul 2020].

13 Bonevski B, Randell M, Paul C, et al. Reaching the hard-to-reach: a systematic review of strategies for improving health and medical research with socially disadvantaged groups. BMC Med Res Methodol 2014;14:42.

14 NutriQuébec team. NutriQuébec Facebook page. Available: https:// www.facebook.com/NutriQuebec/

15 Lemieux V. Pour qu'on se comprenne: guide de littératie en santé. Available: https://santemontreal.qc.ca/professionnels/drsp/ publications/publication-description/publication/pour-quon-secomprenne-guide-de-litteratie-en-sante/

16 Lafrenière $\mathrm{J}$, Laramée $\mathrm{C}$, Robitaille $\mathrm{J}$, et al. Assessing the relative validity of a new, web-based, self-administered $24 \mathrm{H}$ dietary recall in a French-Canadian population. Public Health Nutr 2018;21:2744-52.

17 Jacques S, Lemieux S, Lamarche B, et al. Development of a web-based 24-h dietary recall for a French-Canadian population. Nutrients 2016;8

18 Lafrenière $\mathrm{J}$, Laramée $\mathrm{C}$, Robitaille $\mathrm{J}$, et al. Relative validity of a webbased, self-administered, 24-h dietary recall to evaluate adherence to Canadian dietary guidelines. Nutrition 2019:57:252-6.

19 Savard C, Lemieux S, Lafrenière J, et al. Validation of a selfadministered web-based 24-hour dietary recall among pregnant women. BMC Pregnancy Childbirth 2018;18:112.

20 Lafrenière $\mathrm{J}$, Couillard $\mathrm{C}$, Lamarche $\mathrm{B}$, et al. Associations between self-reported vegetable and fruit intake assessed with a new webbased 24-h dietary recall and serum carotenoids in free-living adults: a relative validation study. J Nutr Sci 2019;8:1-9.

21 Lafrenière $\mathrm{J}$, Lamarche $\mathrm{B}$, Laramée $\mathrm{C}$, et al. Validation of a newly automated web-based 24-hour dietary recall using fully controlled feeding studies. BMC Nutr 2017;3:34.

22 Moshfegh AJ, Rhodes DG, Baer DJ, et al. The US department of agriculture automated Multiple-Pass method reduces bias in the collection of energy intakes. Am J Clin Nutr 2008;88:324-32.

23 Garriguet D. Diet quality in Canada. Health Rep 2009;20:41-52.

24 Carbonneau E, Lamarche B, Lafrenière J, et al. Are French Canadians able to accurately self-rate the quality of their diet? insights from the PREDISE study. Appl Physiol Nutr Metab 2019;44:293-300.

25 Bradette-Laplante M, Carbonneau Élise, Provencher V, et al. Development and validation of a nutrition knowledge questionnaire for a Canadian population. Public Health Nutr 2017;20:1184-92.

26 Carbonneau E, Bradette-Laplante M, Lamarche B, et al. Development and validation of the food liking questionnaire in a French-Canadian population. Nutrients 2017;9:1337.

27 Carbonneau E, Bradette-Laplante M, Lamarche B, et al. Social support for healthy eating: development and validation of a questionnaire for the French-Canadian population. Public Health Nutr 2018;21:2360-6.

28 Carbonneau E, Carbonneau N, Lamarche B, et al. Validation of a French-Canadian adaptation of the intuitive eating Scale-2 for the adult population. Appetite 2016;105:37-45.

29 Carbonneau E, Robitaille J, Lamarche B, et al. Development and validation of the perceived food environment questionnaire in a French-Canadian population. Public Health Nutr 2017;20:1914-20.

30 Côté M, Harrison S, Lapointe A, et al. A cross-sectional survey examining motivation and beliefs to participating in a web-based prospective cohort study on nutrition and health among individuals with a low socioeconomic status. BMC Public Health 2020;20:348.

31 Côté M, Lapointe A, Laramée C, et al. Beliefs related to participation in a large web-based prospective survey on diet and health among individuals with a low socioeconomic status: qualitative study. JMIR Form Res 2019;3:e13854.

32 NutriQuébec team. NutriQuébec website. Available: http:// nutriquebec.com/en/

33 PULSAR. PULSAR, 2019. Available: https://pulsar.ca/en?lang=en

34 Garratt AM, Ruta DA, Abdalla MI, et al. The SF36 health survey questionnaire: an outcome measure suitable for routine use within the NHS? BMJ 1993;306:1440-4.

35 Godin G, Bélanger-Gravel A, Paradis A-marie, et al. A simple method to assess fruit and vegetable intake among obese and non-obese individuals. Can J Public Health 2008;99:494-8.

36 Vézina-Im L-A, Godin G, Couillard C, et al. Validity and reliability of a brief self-reported questionnaire assessing fruit and vegetable consumption among pregnant women. BMC Public Health 2016;16:982.
37 Blais FC, Gendron L, Mimeault V, et al. [Evaluation of insomnia: validity of 3 questionnaires]. Encephale 1997;23:447-53.

38 Buysse DJ, Reynolds CF, Monk TH, et al. The Pittsburgh sleep quality index: a new instrument for psychiatric practice and research. Psychiatry Res 1989;28:193-213.

39 Statistics Canada. Census program. version current 9 June 2020 [online]. Available: https://www12.statcan.gc.ca/censusrecensement/index-eng.cfm [Accessed 13 Jul 2020].

40 Statistics Canada. Canadian health measures survey. version current 4 Mars 2020 [online]. Available: https://www.statcan.gc.ca/eng/ survey/household/5071 [Accessed 13 Jul 2020].

41 Godin G, Shephard R. Godin leisure-time exercise questionnaire. Med Sci Sports Exerc 1997;26:S36-8.

42 Amireault S, Godin G. The Godin-Shephard leisure-time physical activity questionnaire: validity evidence supporting its use for classifying healthy adults into active and insufficiently active categories. Percept Mot Skills 2015;120:604-22.

43 Wareham NJ, Jakes RW, Rennie KL, et al. Validity and repeatability of a simple index derived from the short physical activity questionnaire used in the European prospective investigation into cancer and nutrition (EPIC) study. Public Health Nutr 2003;6:407-13.

44 Khaw K-T, Jakes R, Bingham S, et al. Work and leisure time physical activity assessed using a simple, pragmatic, validated questionnaire and incident cardiovascular disease and all-cause mortality in men and women: the European prospective investigation into cancer in Norfolk prospective population study. Int J Epidemiol 2006;35:1034-43.

45 Perneger TV, Leplège A, Etter JF, et al. Validation of a Frenchlanguage version of the mos 36-Item short form health survey (SF36) in young healthy adults. J Clin Epidemiol 1995;48:1051-60.

46 Kelly MP, Barker M. Why is changing health-related behaviour so difficult? Public Health 2016;136:109-16.

47 Carroll R, Ruppert D, Stefanski L, et al. Measurement error in nonlinear models. New York: Chapman and Hall/CRC 2006.

48 Tooze JA, Kipnis V, Buckman DW, et al. A mixed-effects model approach for estimating the distribution of usual intake of nutrients: the NCl method. Stat Med 2010;29:2857-68.

49 Tooze JA, Midthune D, Dodd KW, et al. A new statistical method for estimating the usual intake of episodically consumed foods with application to their distribution. J Am Diet Assoc 2006;106:1575-87.

50 National Cancer Institute. Usual dietary intakes: the NCl method, 2020. Available: https://epi.grants.cancer.gov/diet/usualintakes/ method.html

51 Cefrio. Portrait numérique des foyers québécois, 2018. Available: https://cefrio.qc.ca/media/2015/netendances2018-portraitnumeriqu efoyersquebecois.pdf

52 Cefrio. Les plus vieux babyboomers et leurs parents 65 ans et plus (1954 et avant), 2018. Available: https://cefrio.qc.ca/media/2188/ netendances-2018-65-ans-et-plus_vf.pdf

53 Cefrio. Génération Z (18-24 ans), 2018. Available: https://cefrio.qc. $\mathrm{ca} / \mathrm{media} / 2184 /$ netendances-2018-18-24-ans_vf.pdf

54 Bernier M. L'utilisation d'Internet chez les Québécois, 2017. Available: http://www.stat.gouv.qc.ca/statistiques/sciencetechnologie-innovation/bulletins/sti-bref-201711-2.pdf

55 Côté M, Lapointe A, Laramée C, et al. Participation NutriQuébec : croyances des personnes issues de milieux défavorisés. Poster presented to the 2019 annual meeting of the Société Québécoise de Lipidologie, Nutrition et Métabolisme (SQLNM), du Réseau de recherche en santé CardioMétabolique, Diabète et Obésité (CMDO) et de COLosSUS, 2018.

56 Kesse-Guyot E, Assmann K, Andreeva V, et al. Lessons learned from methodological validation research in E-Epidemiology. JMIR Public Health Surveill 2016;2:e160.

57 Kesse-Guyot E, Andreeva V, Castetbon K, et al. Participant profiles according to recruitment source in a large web-based prospective study: experience from the Nutrinet-Santé study. J Med Internet Res 2013:15:e205.

58 Whitaker C, Stevelink S, Fear N. The use of Facebook in recruiting participants for health research purposes: a systematic review. $J$ Med Internet Res 2017;19:e290.

59 Topolovec-Vranic J, Natarajan K. The use of social media in recruitment for medical research studies: a scoping review. J Med Internet Res 2016;18:e286.

60 Clarity group - McMaster University. Tool to assess risk of bias in cohort studies, 2018. Available: https://www.evidencepartners. com/wp-content/uploads/2017/09/Tool-to-Assess-Risk-of-Bias-inCohort-Studies.pdf 